\title{
Mitochondrial haplogroup $U$ is associated with a reduced risk to develop exfoliation glaucoma in the German population
}

\author{
Christiane Wolf ${ }^{\dagger}$, Eugen Gramer ${ }^{2 \dagger}$, Bertram Müller-Myhsok ${ }^{3}$, Francesca Pasutto ${ }^{4}$, Bernd Wissinger ${ }^{1}$, \\ Nicole Weisschuh ${ }^{1 *}$
}

\begin{abstract}
Background: Various lines of evidence demonstrate the involvement of mitochondrial dysfunction in the pathogenesis of glaucoma. Therefore, mitochondrial DNA is a promising candidate for genetic susceptibility studies on glaucoma. To test the hypothesis that mitochondrial haplogroups influence the risk to develop glaucoma, we genotyped 12 single-nucleotide polymorphisms that define the European mitochondrial DNA haplogroups in healthy controls and two German patient cohorts with either exfoliation glaucoma or the normal tension subgroup of primary open angle glaucoma.
\end{abstract}

Results: Mitochondrial haplogroup $\mathrm{U}$ was significantly under-represented in patients with exfoliation glaucoma (8.3\% compared with $18.9 \%$ in controls; $p=0.004)$.

Conclusions: People with haplogroup $U$ have a lower risk to develop exfoliation glaucoma. Our results substantiate the suggestion that mitochondrial alterations have an impact on the etiology of glaucoma.

\section{Background}

Glaucoma is among the leading causes of blindness in elderly people of western European ancestry [1]. In the last ten years a few genes and a number of unsolved gene loci for open angle glaucoma have been identified based on the analyses of mendelian forms of glaucoma. These however only comprise a small fraction of the total glaucoma patient population. None of these genes or loci has been shown to have a relevant impact on the glaucoma population as a whole. The strong hereditary component in glaucoma most likely results from multigenic inheritance involving multiple susceptibility genes [2].

Diverse pathophysiological mechanisms are discussed to be involved in glaucoma including vascular dysregulation, excitotoxicity, autoimmunity and oxidative stress [3-6]. The latter is relevant to neuronal damage in the glaucomatous retina and optic nerve head since it triggers mitochondrial dysfunction and leads to retinal

\footnotetext{
* Correspondence: nicole.weisschuh@uni-tuebingen.de

† Contributed equally

${ }^{1}$ Centre for Ophthalmology, Institute for Ophthalmic Research, Molecular Genetics Laboratory, Tuebingen, Germany
}

ganglion cell (RGC) death in a cell culture model [7]. The pathogenic role of reactive oxygen species in glaucoma is supported by various experimental findings, such as an increase of the oxidative stress markers superoxide dismutase, catalase, and glutathione peroxidase in the aqueous humor of patients with primary open angle glaucoma and exfoliation glaucoma [8,9]. A significant correlation between oxidative DNA damage in the trabecular meshwork and intraocular pressure (IOP) increase and visual field defects was observed in glaucomatous patients [10]. In an independent study, a significant reduction of mitochondrial respiratory function in peripheral blood cells was observed in glaucoma patients when compared to age-matched healthy controls [11]. Another study showed that the exposure of RGCs to elevated hydrostatic pressure resembling an elevated intraocular pressure results in altered mitochondrial fission [12].

The involvement of mitochondrial dysfunction in glaucoma can also be certified by maternal inheritance. Several studies have shown that a maternal family history is more frequent than a paternal history in glaucoma [13-16] which suggests a contribution of

(c) 2010 Wolf et al; licensee BioMed Central Ltd. This is an Open Access article distributed under the terms of the Creative Commons 
mitochondrial DNA (mtDNA) to glaucoma pathogenesis. In fact, an increased frequency of nonsynonymous mtDNA sequence changes in patients with primary open angle glaucoma has been shown [17]. However, this report describes a relatively small number of patients from a restricted ethnic population and confirmation in other populations is still lacking.

MtDNA is exposed to a higher mutation rate compared to nuclear DNA as it is not protected by histones. Furthermore, the repair mechanisms in mitochondria are not as efficient as those in the nucleus $[18,19]$. Among the numerous mutations that have accumulated in mtDNA during evolution there are several ethnic specific single nucleotide polymorphisms (SNPs) that enable the definition of discrete and region specific subdivisions of the human population called mitochondrial haplogroups (mtHgs). More than $90 \%$ of European mtDNAs belong to nine haplogroups $(\mathrm{H}, \mathrm{V}, \mathrm{U}, \mathrm{K}, \mathrm{J}, \mathrm{T}$, W, I and X), which are highly specific for Western Eurasia [20]. Specific mtHgs might reflect functional differences in energy metabolism and were therefore linked with human diseases like neurodegenerative disorders [21] or cancer [22]. Polymorphisms in mtDNA might also represent modifier factors as has been shown in Leber's hereditary optic neuropathy (LHON) where mtHgs contribute to the phenotypic expression of mtDNA mutations [23-25].

The relationship of $\mathrm{mtHg}$ distribution and glaucoma has not been subject of comprehensive studies so far. One study was based on the phylogenetic network for European mtDNA [26]. The authors genotyped 140 patients with primary open angle glaucoma and 75 healthy controls but could not detect a significant difference of mtHgs frequencies between patients and controls [27]. A second study in the Saudi-Arab population [28] compared the prevalence of region specific mtHgs in 552 healthy controls with a patient cohort that was composed of three different glaucoma subtypes (49 patients with primary open angle glaucoma, 29 cases with primary angle closure glaucoma and 29 cases with exfoliation glaucoma). Like in the first study, the authors were not able to identify significant differences between patients and controls for all mitochondrial haplogroups tested except for the 29 primary angle closure glaucoma patients. The authors however admitted that the statistical significance reached for this patient group might have been accidental due to the small number of cases.

The aim of our study was to evaluate the distribution of mtHgs in two German cohorts with exfoliation glaucoma $(\mathrm{n}=157)$ and the normal tension subgroup of primary open angle glaucoma $(\mathrm{n}=272)$. The frequencies of ten common European mtHgs in both cohorts were compared with those in a control group $(\mathrm{n}=$ 249) of German origin.

\section{Results and Discussion}

We studied the mitochondrial haplogroup distribution among 272 patients with the normal tension subgroup of primary open angle glaucoma (NTG) and 157 patients with exfoliation glaucoma (XFG). Two hundred and forty-nine individuals matched for age, gender and ethnicity and with exclusion of glaucoma served as control group.

Ten major European haplogroups (HV, H, I, J, K, T, $\mathrm{U}, \mathrm{V}, \mathrm{W}$ and $\mathrm{X}$ ) were observed in both patient groups and in controls (Table 1). All frequencies observed in the control group were consistent with previous studies of European populations [29-31].

When comparing the frequencies of mitochondrial haplogroups between cases and controls, we observed that haplogroup $\mathrm{U}$ was clearly under-represented in XFG patients (8.3\% compared to $18.9 \%$ in controls).

Table 1 Haplogroup distribution in patients and controls

\begin{tabular}{|c|c|c|c|c|c|c|c|c|c|c|c|}
\hline \multirow[b]{2}{*}{$\mathrm{mtHg}$} & \multirow{2}{*}{$\begin{array}{l}\text { Controls }(n=249) \\
f\end{array}$} & \multicolumn{5}{|c|}{ NTG $(n=272)$} & \multicolumn{5}{|c|}{ XFG $(n=157)$} \\
\hline & & $f$ & $p$ & OR & L95 & U95 & $f$ & $\mathrm{p}$ & OR & L95 & U95 \\
\hline$\overline{\mathrm{H}}$ & 0.450 & 0.434 & 0.725 & 0.937 & 0.663 & 1.324 & 0.491 & 0.475 & 1.177 & 0.790 & 1.756 \\
\hline U & 0.189 & 0.132 & 0.093 & 0.656 & 0.410 & 1.049 & 0.083 & 0.004 & 0.388 & 0.204 & 0.737 \\
\hline $\mathrm{T}$ & 0.108 & 0.147 & 0.193 & 1.418 & 0.845 & 2.379 & 0.115 & 0.872 & 1.065 & 0.570 & 1.991 \\
\hline J & 0.068 & 0.063 & 0.860 & 0.910 & 0.459 & 1.804 & 0.070 & 1.000 & 1.028 & 0.476 & 2.222 \\
\hline K & 0.056 & 0.099 & 0.075 & 1.850 & 0.956 & 3.578 & 0.083 & 0.312 & 1.515 & 0.704 & 3.265 \\
\hline$\overline{\mathrm{O}}$ & 0.040 & 0.0 & & & & & 0.006 & & & & \\
\hline V & 0.024 & 0.033 & & & & & 0.051 & & & & \\
\hline W & 0.020 & 0.015 & & & & & 0.032 & & & & \\
\hline $\mathrm{HV}$ & 0.016 & 0.018 & & & & & 0.038 & & & & \\
\hline 1 & 0.016 & 0.018 & & & & & 0.013 & & & & \\
\hline$x$ & 0.012 & 0.018 & & & & & 0.019 & & & & \\
\hline
\end{tabular}

O, unclassified mitochondrial haplogroups; f, frequency; OR, odds ratio; L95, confidence interval 95\% lower bound; U95, confidence interval 95\% upper bound. Odds ratios were calculated only for haplogroups with a frequency $>5 \%$. The only significant $p$-value is in bold. 
Statistical analysis with Fisher's exact test revealed that this difference was significant $(\mathrm{p}=0.004)$.

In NTG patients, haplogroup U was slightly underrepresented (13.2\% compared to $18.9 \%$ in controls) whereas haplogroup $\mathrm{T}$ was slightly over-represented (14.7\% compared to $10.8 \%$ in controls). However, these differences were not significant (Table 1). Either mitochondrial haplogroups are not associated with this specific disease entity or NTG is genetically more complex than XFG and therefore larger sample sizes would be required to detect subtle differences in the distribution of mtHgs. As has been shown by Samuels and co-workers [32] subtle changes in haplogroup frequency will require cohorts that should be at least twice as large as our patient cohorts. This holds true especially for lowfrequency mtHgs which we excluded a priori from statistical analysis.

There is growing evidence that certain mtHgs are associated with distinct diseases. In Europe, some mtHgs have been found to be protective against neurodegenerative diseases. Haplogroups J and $\mathrm{K}$ are underrepresented in Parkinson disease [33] and haplogroup U is underrepresented in female patients with Alzheimer disease [34]. However, the contribution of a specific mitochondrial haplogroup to disease mechanisms is yet difficult to explain. Whereas it seems unlikely that single SNPs alter the efficiency of mitochondrial energy production enough to cause a specific disease, there is evidence that certain mtDNA genetic backgrounds can modify primary mutations: Several independent studies support a role for haplogroup $\mathrm{J}$ in the expression of certain LHON mutations [23-25].

We cannot rule out that other than the genotyped mtDNA variants are present in our patients as we did not evaluate the whole mitochondrial genome. Further studies should focus on this point as it may provide more insight into the association of $\mathrm{mtHgs}$ with glaucoma.

So far, only two studies dealt with association of mtHgs and glaucoma, and both are not ideally suited to be compared with our results. The first study analyzed patients of British origin [27] and the second focussed on patients from Saudi Arabia [28]. Due to the different geographical distribution of $\mathrm{mtHgs}$ our results from a middle European population cannot be directly compared with the study performed in Saudi Arabs. The British study, on the other hand, focussed on primary open angle glaucoma patients and not exfoliation glaucoma or normal tension glaucoma.

Apart from the $\mathrm{mtHg}$ distribution, our study provides a second line of evidence that substantiates a possible involvement of mitochondrial DNA in glaucoma pathogenesis. Within the NTG patients, a maternal history of glaucoma $(17 \%)$ is more prevalent than a paternal history (8\%) (data not shown). This difference is statistically significant $(\mathrm{p}=0.01)$. Within the XFG patients, $18 \%$ have an affected mother whereas only $10 \%$ report an affected father (data not shown). This difference does not reach significance level $(\mathrm{p}=0.13)$ but indicates a higher prevalence for maternal history in XFG glaucoma. Although several sources of bias might influence these results (recall bias; closer offspring contact with mothers than fathers; greater life expectancy of females that increases the rate of affected women in a late onset disease such as glaucoma), a higher prevalence of maternal history in glaucoma has been reported repeatedly [13-16] and alternative mechanisms for this observation (e.g. imprinting) have not yet been identified.

Although the association of haplogroup U with XFG reached significance level, it is important to point out that the power of our study is still relatively limited. In Germany, almost half of any study population belongs to the predominant haplogroup $\mathrm{H}$, thus limiting the power to detect an association among the remaining haplogroups due to a rigorous reduction of these sample sizes.

\section{Conclusions}

Our data indicate that mitochondrial haplogroup $U$ is associated with a reduced risk to develop exfoliation glaucoma in the German population. Further studies in larger cohorts are needed to confirm this observation. Sequencing the entire mitochondrial genome might lead to the identification of other than $\mathrm{mtHg}$-defining variants that contribute to the disease phenotype. The incorporation of data from genome-wide association studies might reveal synergistic interactions of $\mathrm{mtHgs}$ with other genes.

\section{Methods}

\section{Study samples}

This study adhered to the tenets of the Declaration of Helsinki. Written informed consent was obtained from all subjects and the study was approved by the ethics committees of the Universities of Tuebingen, Wuerzburg and Erlangen-Nuremberg.

The entire study population comprised 678 subjects of German origin including 272 patients with normal tension glaucoma (NTG), 157 patients with exfoliation glaucoma (XFG) and 249 healthy controls.

The NTG cohort comprised 177 women and 95 men. The mean age of individuals was $65.0 \pm 13.0$ years (median 67 years). NTG was defined by (1) the presence of typical glaucomatous optic neuropathy with corresponding visual field loss, (2) open drainage angles on gonioscopy, (3) absence of a secondary cause for glaucomatous optic neuropathy, such as previously elevated IOP after trauma, a period of steroid administration or 
uveitis, and (4) IOP measures of untreated NTG continuously $21 \mathrm{mmHg}$ or lower on repeated diurnal testing (five readings between 8:00 AM and 6:00 PM). The median of readings was required to be $21 \mathrm{~mm} \mathrm{Hg}$ or less, with no reading above $24 \mathrm{~mm} \mathrm{Hg}$ and no more than one reading of 23 or $24 \mathrm{~mm} \mathrm{Hg}$. IOP readings were correlated with corneal thickness. Patients did not have evidence of high myopia or congenital ocular abnormality and had no other cause than glaucoma for disc changes and visual field loss. Disc size and parameters were evaluated by confocal examination (Heidelberg Retina Tomograph). To minimize interobserver variability, more than $95 \%$ of patients were examined by the same ophthalmologist. All patients had a long term follow-up to ensure diagnosis of NTG with a maximum of certainty. In large part, NTG patients underwent a neurological examination to exclude an intracerebral expansion. Sonography was used to rule out aortic stenosis.

The XFG cohort comprised 89 women and 68 men. The mean age in this group was $72.5 \pm 8.7$ years (median 72 years). All patients diagnosed with exfoliation syndrome in this study showed manifest exfoliation deposits in the anterior chamber. All of them met the criterion of XFG as they showed intraocular pressure (IOP) exceeding $21 \mathrm{~mm} \mathrm{Hg}$ and typical glaucomatous optic neuropathy with compatible visual field loss.

Ethnicity of XFG and NTG patients was assessed for the last three generations by standardized questionnaire and self-reporting. Family history information was obtained from 200 NTG patients and 157 XFG patients. This information originated from questionnaires completed by the patients themselves.

The control cohort comprised 149 women and 100 men and was matched with the patient cohorts for age, gender distribution and geographical origin. The average age in controls was $66.8 \pm 13.3$ years (median 68 years). Slit lamp microscopy in mydriasis was performed to exclude presence of exfoliation deposits on intraocular tissues. IOPs were in the normal range $(<21 \mathrm{~mm} \mathrm{Hg})$ and they had no glaucomatous disc damage. Controls had no family history of glaucoma.

\section{Isolation of DNA and genotyping}

DNA was extracted from peripheral blood lymphocytes using the Magnetic Separation Module I from Chemagen using DNA chemistry (Chemagic DNA Blood Kit Special; Chemagen AG, Baesweiler, Germany).

The TaKaRa LA PCR Amplification Kit (Takara Bio Inc., Shiga, Japan) was used according to the manufacturer's protocol to amplify a $12612 \mathrm{bp}$ fragment of mtDNA comprising all polymorphic sites that were used to characterize and distinguish the European haplogroups H, V, HV, U, K, J, T, W, I and X (primers are given in Table 2). Specific extension primers were designed to genotype mtHg specific SNPs (Table 2). Two separate multiplex primer extension reactions (MPE R1 and MPE R2) each covering 6 informative SNPs were performed using the ABI PRISM SNaPshot Multiplex Kit (Applied Biosystems (ABI), Weiterstadt, Germany). Capillary-based electrophoretic separation of multiplex primer extension products was performed on a sequence detection system (ABI 7500). Sequence data were analyzed using ABI PRISM GeneMapper Software version 3.7. SNPs for haplogroup typing were selected as previously reported and are listed in Table $3[35,36]$. Haplogroups that could not be assigned to one of the major European haplogroups with this scheme were designated as "others" (O).

Table 2 List of primers used for amplification of mtDNA and primer extension reactions

\begin{tabular}{|c|c|c|}
\hline Reaction & Primer sequence & Nucleotide position \\
\hline \multirow[t]{2}{*}{ LD PCR } & forward: ACAACCCTTCGCTGACGCCATA & - \\
\hline & reverse: GGTGGTACCCAAATCTGCTTCC & - \\
\hline \multirow[t]{6}{*}{ MPE R1 } & AGCCATCGCTGTAGTATA & 14470 \\
\hline & ACCTGAGTAGGCCTAGAAATAAACAT & 4580 \\
\hline & $(\mathrm{A})_{8} \mathrm{CTACACGACACGTACTACGTTGTAGC}$ & 7028 \\
\hline & (A) ${ }_{12}$ GTTTATTACTCTITITTGAATGTTGTCAAA & 10034 \\
\hline & $(\mathrm{A})_{23} \mathrm{CGACTCATTAAATTATGATAATCATAT}$ & 10463 \\
\hline & $(\mathrm{A})_{27}$ TACTCAAATGGGCCTGTCCTTGTAGTATAAA & 15904 \\
\hline \multirow[t]{6}{*}{ MPE R2 } & TGACCCCAATACGCAAAA & 14766 \\
\hline & $(\mathrm{A})_{5}$ TCCATTGGTCTTAGGCCCCAA & 12308 \\
\hline & $(\mathrm{A})_{12}$ TGTTAGCGGTTAGGCGTACGGC & 8994 \\
\hline & $(\mathrm{A})_{17} \mathrm{GTGACTACAAAAAGGATTAGACTGA}$ & 10398 \\
\hline & (A) ${ }_{16} \mathrm{CTTCCTACCACTCACCCTAGCATTACTTATATGA}$ & 4216 \\
\hline & $(\mathrm{A})_{28} \mathrm{GGCCACCTACTCATGCACCTAATTGGAAGC}$ & 9055 \\
\hline
\end{tabular}

LD, long distance; MPE R, multiplex primer extension reaction. Nucleotide position according to the revised Cambridge reference sequence (GenBank: J01415.2). 
Table 3 Selected SNPs for discrimination of ten common European haplogroups

\begin{tabular}{ccccccccccc}
\hline Nucleotide position & $\mathbf{H}$ & $\mathbf{V}$ & $\mathbf{H V}$ & $\mathbf{W}$ & $\mathbf{U}$ & $\mathbf{K}$ & $\mathbf{I}$ & $\mathbf{X}$ & $\mathbf{T}$ & $\mathbf{J}$ \\
\hline 14470 & $\mathrm{~T}$ or $\mathrm{A}$ & $\mathrm{T}$ & $\mathrm{T}$ & $\mathrm{T}$ & $\mathrm{T}$ & $\mathrm{T}$ & $\mathrm{T}$ & $\mathrm{C}$ & $\mathrm{T}$ & $\mathrm{T}$ \\
4580 & $\mathrm{G}$ & $\mathrm{G}$ or A & $\mathrm{G}$ & $\mathrm{G}$ & $\mathrm{G}$ & $\mathrm{G}$ & $\mathrm{G}$ & $\mathrm{G}$ & $\mathrm{G}$ & $\mathrm{G}$ \\
7028 & $\mathrm{C}$ & $\mathrm{T}$ & $\mathrm{T}$ & $\mathrm{T}$ & $\mathrm{T}$ & $\mathrm{T}$ & $\mathrm{T}$ & $\mathrm{T}$ & $\mathrm{T}$ & $\mathrm{T}$ \\
10034 & $\mathrm{~T}$ & $\mathrm{~T}$ & $\mathrm{~T}$ & $\mathrm{~T}$ & $\mathrm{~T}$ & $\mathrm{~T}$ & $\mathrm{C}$ & $\mathrm{T}$ & $\mathrm{T}$ & $\mathrm{T}$ \\
10463 & $\mathrm{~T}$ & $\mathrm{~T}$ & $\mathrm{~T}$ & $\mathrm{~T}$ & $\mathrm{~T}$ & $\mathrm{~T}$ & $\mathrm{~T}$ & $\mathrm{~T}$ & $\mathrm{C}$ & $\mathrm{T}$ \\
15904 & $\mathrm{C}$ & $\mathrm{T}$ & $\mathrm{C}$ & $\mathrm{C}$ & $\mathrm{C}$ & $\mathrm{C}$ & $\mathrm{C}$ & $\mathrm{C}$ & $\mathrm{C}$ & $\mathrm{C}$ \\
14766 & $\mathrm{C}$ & $\mathrm{C}$ & $\mathrm{C}$ & $\mathrm{T}$ & $\mathrm{T}$ & $\mathrm{T}$ & $\mathrm{T}$ & $\mathrm{T}$ & $\mathrm{T}$ & $\mathrm{T}$ \\
12308 & $\mathrm{~A}$ & $\mathrm{~A}$ & $\mathrm{~A}$ & $\mathrm{~A}$ & $\mathrm{G}$ & $\mathrm{G}$ & $\mathrm{A}$ & $\mathrm{A}$ & $\mathrm{A}$ & $\mathrm{A}$ \\
8994 & $\mathrm{G}$ & $\mathrm{G}$ & $\mathrm{G}$ & $\mathrm{A}$ & $\mathrm{G}$ & $\mathrm{G}$ & $\mathrm{G}$ & $\mathrm{G}$ & $\mathrm{G}$ & $\mathrm{G}$ \\
10398 & $\mathrm{~A}$ & $\mathrm{~A}$ & $\mathrm{~A}$ & $\mathrm{~A}$ & $\mathrm{~A}$ & $\mathrm{G}$ or A & $\mathrm{G}$ & $\mathrm{A}$ & $\mathrm{A}$ & $\mathrm{G}$ \\
4216 & $\mathrm{~T}$ or C & $\mathrm{T}$ & $\mathrm{T}$ & $\mathrm{T}$ & $\mathrm{T}$ & $\mathrm{T}$ & $\mathrm{T}$ & $\mathrm{T}$ & $\mathrm{C}$ & $\mathrm{C}$ \\
9055 & $\mathrm{G}$ & $\mathrm{G}$ & $\mathrm{G}$ & $\mathrm{G}$ & $\mathrm{G}$ & $\mathrm{A}$ & $\mathrm{G}$ & $\mathrm{G}$ & $\mathrm{G}$ & $\mathrm{G}$ \\
\hline
\end{tabular}

Nucleotide position according to the revised Cambridge reference sequence (GenBank: J01415.2).

\section{Statistical analysis}

Frequencies of mtHgs in patients and controls were tested for independence using Fisher's exact test. Only mtHgs with a frequency $>0.05$ were tested. A p-value $<$ 0.05 was considered significant. Multiple testing errors were corrected by the Bonferroni method. As five mtHgs were tested and the haplogroup distribution was compared with the controls among each of the two glaucoma subgroups, the significance level was reduced to $\alpha=0.005$.

Significance for deviation from a fifty-fifty-distribution of maternal and paternal disease history was calculated using a $\mathrm{X}^{2}$ test.

\section{Acknowledgements}

This work was supported by the Ernst-und-Berta-Grimmke-Stiftung.

\section{Author details}

${ }^{1}$ Centre for Ophthalmology, Institute for Ophthalmic Research, Molecular Genetics Laboratory, Tuebingen, Germany. ${ }^{2}$ University Eye Hospital, JuliusMaximilians-University, Wuerzburg, Germany. ${ }^{3}$ Max Planck Institute of Psychiatry, Munich, Germany. ${ }^{4}$ Institute of Human Genetics, FriedrichAlexander-University Erlangen-Nuremberg, Erlangen, Germany.

\section{Authors' contributions}

CW carried out the genotyping, performed the statistical analysis, drafted the manuscript and participated in the design of the study. EG performed the clinical examination of all patients and participated in the coordination of the study. BM-M participated in the statistical analysis. FP participated in the recruitment of control subjects. BW participated in study design and helped drafting the manuscript. NW conceived of the study, and participated in its design and coordination and helped to draft the manuscript. All authors read and approved the final manuscript.

Received: 4 June 2009

Accepted: 28 January 2010 Published: 28 January 2010

\section{References}

1. Quigley HA, Broman AT: The number of people with glaucoma worldwide in 2010 and 2020. Br J Ophthalmol 2006, 90:262-267.

2. Gong G, Kosoko-Lasaki S, Haynatzki G, Lynch HT, Lynch JA, Wilson MR: Inherited, familial and sporadic primary open-angle glaucoma. J Natl Med Assoc 2007, 99:559-563.
3. Flammer J, Mozaffarieh M: What is the present pathogenetic concept of glaucomatous optic neuropathy?. Sun Ophthalmol 2007, 52(Suppl 2):162-173.

4. Casson RJ: Possible role of excitotoxicity in the pathogenesis of glaucoma. Clin Experiment Ophthalmol 2006, 34:54-63.

5. Grus FH, Joachim SC, Wuenschig D, Rieck J, Pfeiffer N: Autoimmunity and glaucoma. J Glaucoma 2008, 17:79-84.

6. Kong GY, Van Bergen NJ, Trounce IA, Crowston JG: Mitochondrial dysfunction and glaucoma. J Glaucoma 2009, 18:93-100.

7. Tezel G, Yang X: Caspase-independent component of retinal ganglion cell death in vitro. Invest Ophthalmol Vis Sci 2004, 45:4049-4059.

8. Ferreira SM, Lerner SF, Brunzini R, Evelson PA, Llesuy SF: Oxidative stress markers in aqueous humor of glaucoma patients. Am J Ophthalmol 2004, 137:62-69.

9. Ferreira SM, Lerner SF, Brunzini R, Evelson PA, Llesuy SF: Antioxidant status in the aqueous humour of patients with glaucoma associated with exfoliation syndrome. Eye 2009, 23:1691-1697.

10. Sacca SC, Pascotto A, Camicione P, Capris P, Izzotti A: Oxidative DNA damage in the human trabecular meshwork: clinical correlation in patients with primary open-angle glaucoma. Arch Ophthalmol 2005, 123:458-463.

11. Abu-Amero KK, Morales J, Bosley TM: Mitochondrial abnormalities in patients with primary open-angle glaucoma. Invest Ophthalmol Vis Sci 2006, 47:2533-2541.

12. Ju WK, Liu Q, Kim KY, Crowston JG, Lindsey JD, Agarwal N, Ellisman MH, Perkins GA, Weinreb RN: Elevated hydrostatic pressure triggers mitochondrial fission and decreases cellular ATP in differentiated RGC-5 cells. Invest Ophthalmol Vis Sci 2007, 48:2145-2151.

13. Morgan RW, Drance SM: Chronic open-angle glaucoma and ocular hypertension. An epidemiological study. Br J Ophthalmol 1975, 59:211-215.

14. Shin $\mathrm{DH}$, Becker $\mathrm{B}$, Kolker AE: Family history in primary open-angle glaucoma. Arch Ophthalmol 1977, 95:598-600.

15. Charliat G, Jolly D, Blanchard F: Genetic risk factor in primary open-angle glaucoma: a case-control study. Ophthalmic Epidemiol 1994, 1:131-138.

16. Nemesure B, Leske MC, He Q, Mendell N: Analyses of reported family history of glaucoma: a preliminary investigation. The Barbados Eye Study Group. Ophthalmic Epidemiol 1996, 3:135-141.

17. Abu-Amero KK, Morales J, Bosley TM: Mitochondrial abnormalities in patients with primary open-angle glaucoma. Invest Ophthalmol Vis Sci 2006, 47:2533-2541.

18. Larsen NB, Rasmussen M, Rasmussen LJ: Nuclear and mitochondrial DNA repair: similar pathways?. Mitochondrion 2005, 5:89-108.

19. Bohr VA, Stevnsner T, de Souza-Pinto NC: Mitochondrial DNA repair of oxidative damage in mammalian cells. Gene 2002, 286:127-134.

20. Torroni A, Petrozzi M, D'Urbano L, Sellitto D, Zeviani M, Carrara F, Carducci C, Leuzzi V, Carelli V, Barboni P, De Negri A, Scozzari R: Haplotype and phylogenetic analyses suggest that one European-specific mtDNA background plays a role in the expression of Leber hereditary optic 
neuropathy by increasing the penetrance of the primary mutations 11778 and 14484. Am J Hum Genet 1997, 60:1107-1121.

21. Raule N, Sevini F, Santoro A, Altilia S, Franceschi C: Association studies on human mitochondrial DNA: methodological aspects and results in the most common age-related diseases. Mitochondrion 2007, 7:29-38.

22. Singh KK, Kulawiec M: Mitochondrial DNA polymorphism and risk of cancer. Methods Mol Biol 2009, 471:291-303.

23. Carelli V, Achilli A, Valentino ML, Rengo C, Semino O, Pala M, Olivieri A, Mattiazzi M, Pallotti F, Carrara F, Zeviani M, Leuzzi V, Carducci C, Valle G, Simionati B, Mendieta L, Salomao S, Belfort R Jr, Sadun AA, Torroni A: Haplogroup effects and recombination of mitochondrial DNA: novel clues from the analysis of Leber hereditary optic neuropathy pedigrees. Am J Hum Genet 2006, 78:564-574.

24. Pello R, Martín MA, Carelli V, Nijtmans LG, Achilli A, Pala M, Torroni A, Gómez-Durán A, Ruiz-Pesini E, Martinuzzi A, Smeitink JA, Arenas J, Ugalde C: Mitochondrial DNA background modulates the assembly kinetics of OXPHOS complexes in a cellular model of mitochondrial disease. Hum Mol Genet 2008, 17:4001-4011.

25. Pierron D, Rocher C, Amati-Bonneau P, Reynier P, Martin-Négrier ML, Allouche S, Batandier C, de Camaret BM, Godinot C, Rotig A, Feldmann D, Bellanne-Chantelot C, Arveiler B, Pennarun E, Rossignol R, Crouzet M, Murail $P$, Thoraval $D$, Letellier $T$ : New evidence of a mitochondrial genetic background paradox: impact of the J haplogroup on the A3243G mutation. BMC Med Genet 2008, 9:41-53.

26. Finnilä S, Lehtonen MS, Majamaa K: Phylogenetic network for European mtDNA. Am J Hum Genet 2001, 68:1475-1484.

27. Andrews R, Ressiniotis T, Turnbull DM, Birch M, Keers S, Chinnery PF, Griffiths PG: The role of mitochondrial haplogroups in primary open angle glaucoma. $\mathrm{Br} J$ Ophthalmol 2006, 90:488-490.

28. Abu-Amero KK, Morales J, Bosley TM, Mohamed GH, Cabrera VM: The role of mitochondrial haplogroups in glaucoma: a study in an Arab population. Mol Vis 2008, 14:518-522.

29. Torroni A, Huoponen K, Francalacci P, Petrozzi M, Morelli L, Scozzari R, Obinu D, Savontaus ML, Wallace DC: Classification of European mtDNAs from an analysis of three European populations. Genetics 1996, 144:1835-1850

30. Wiesbauer M, Meierhofer D, Mayr JA, Sperl W, Paulweber B, Kofler B: Multiplex primer extension analysis for rapid detection of major European mitochondrial haplogroups. Electrophoresis 2006, 27:3864-3868.

31. Kofler B, Mueller EE, Eder W, Stanger O, Maier R, Weger M, Haas A, Winker R, Schmut O, Paulweber B, Iglseder B, Renner W, Wiesbauer M Aigner I, Santic D, Zimmermann FA, Mayr JA, Sperl W: Mitochondrial DNA haplogroups $T$ is associated with coronary artery disease and diabetic retinopathy: a case control study. BMC Med Genet 2009, 10:35-41.

32. Samuels DC, Carothers AD, Horton R, Chinnery PF: The Power to Detect Disease Associations with Mitochondrial DNA Haplogroups. Am J Hum Genet 2006, 78:713-720.

33. Walt van der JM, Nicodemus KK, Martin ER, Scott WK, Nance MA, Watts RL, Hubble JP, Haines JL, Koller WC, Lyons K, Pahwa R, Stern MB, Colcher A, Hiner BC, Jankovic J, Ondo WG, Allen FH Jr, Goetz CG, Small GW, Mastaglia F, Stajich JM, McLaurin AC, Middleton LT, Scott BL, Schmechel DE, Pericak-Vance MA, Vance JM: Mitochondrial polymorphisms significantly reduce the risk of Parkinson disease. Am J Hum Genet 2003, 72:804-811.

34. Walt van der JM, Dementieva YA, Martin ER, Scott WK, Nicodemus KK, Kroner CC, Welsh-Bohmer KA, Saunders AM, Roses AD, Small GW Schmechel DE, Murali Doraiswamy P, Gilbert JR, Haines JL, Vance JM, Pericak-Vance MA: Analysis of European mitochondrial haplogroups with Alzheimer disease risk. Neurosci Lett 2004, 365:28-32.

35. Torroni A, Lott MT, Cabell MF, Chen Y-S, Lavergne L, Wallace DC: MtDNA and the origin of Caucasians: identification of ancient Caucasian-specific haplogroups, one of which is prone to a recurrent somatic duplication in the Dloop region. Am J Hum Genet 1994, 55:760-776.

36. Macaulay V, Richards M, Hickey E, Vega E, Cruciani F, Guida V, Scozzari R, Bonné-Tamir B, Sykes B, Torroni A: The emerging tree of West Eurasian mtDNAs: a synthesis of control-region sequences and RFLPs. Am J Hum Genet 1999, 64:232-249.

doi:10.1186/1471-2156-11-8

Cite this article as: Wolf et al:: Mitochondrial haplogroup $U$ is associated with a reduced risk to develop exfoliation glaucoma in the German population. BMC Genetics 2010 11:8.

\section{Submit your next manuscript to BioMed Central and take full advantage of:}

- Convenient online submission

- Thorough peer review

- No space constraints or color figure charges

- Immediate publication on acceptance

- Inclusion in PubMed, CAS, Scopus and Google Scholar

- Research which is freely available for redistribution 